\title{
Measuring low concentrations of asbestos fibers in environmental air samples from asbestos roofed houses
}

\author{
K.A. Renton and E.A. Garton \\ The National Center of Occupational Health, Johannesburg 2000 \\ South Africa
}

\begin{abstract}
Inhaling asbestos fibers may cause asbestosis, cancer of the lungs or pleural mesothelioma. Air samples in asbestos roofed houses in historically disadvantaged suburbs of Soweto near Johannesburg, were taken to assess the asbestos in air concentrations to determine possible health risks. Two methods to determine asbestos concentrations were used: the Asbestos International Association recommended technical method 2 (AIA RTM 2) using a scanning electron microscope (SEM) and AIA RTM 1 for phase contrast microscopy (PCM). The number of fields to be counted for the AIA RTM 2 method was investigated. We found that the number of fields to be counted could not be reduced. Several countable asbestos fibers were found attached to particles indicating that the fibers may have originated from the asbestos cement roofs.

We found the average asbestos levels in 14 houses to be 0.1 fibers per liter. This result is below the limit of quantification and is therefore a qualitative finding. No asbestos fibers were detected in non-asbestos roofed house air samples by the AIA RTM 2 method. The PCM method was found to be poorly suited to the measurement of low asbestos fiber concentrations in air. There was almost no correlation between the two methods of measurement as the PCM method counted 'false positive' fibers, which looked like asbestos but were not.
\end{abstract}




\section{Environmental Health Risk}

\section{Introduction}

Environmental exposure to asbestos has been studied in South Africa in two communities involved in mining and processing asbestos. In Prieska, formerly a predominantly crocidolite producing area, 9 cases of mesothelioma in women were found in a cohort of 5898 people representing an incidence of 0.17 per thousand (1). It would be reasonable to expect that these cases were environmentally induced.

In 1987 at Mafefe, 12000 people lived around a crocidolite and amosite producing mine that had closed down in 1980. Thirty four percent of the adults with only 'reported' environmental exposure had radiological signs of asbestos pathology. The average fiber concentration measured during the survey in 1987 was $12 \mathrm{f} /$ liter (2).

There is a concern that infants are exposed to asbestos from the roofs, which are present on about half of the houses in Soweto (3). Two limited studies of asbestos fiber in Soweto have shown an average concentration of 3 fibers per liter using phase contrast microscopy but found much higher concentrations of 72 and $127 \mathrm{f} /$ liter near an asbestos cement sanding operation (4). Colleagues at the $\mathrm{NCOH}$ have expressed concern that these measurements were below the limit of quantification of $100 \mathrm{f} /$ liter for the Asbestos International Association Recommended Technical Method (AIA RTM) 1 method and therefore were not accurate.

During 2000 the $\mathrm{NCOH}$ began a study designed to more accurately assess the environmental exposure to asbestos in Soweto and address the methodology issue mentioned above.

Most literature references of asbestos analysis used either a phase contrast microscope (PCM) or transmission electron microscope (TEM). The SEM has not been used extensively for asbestos analysis and therefore in this study the number and selection of the fields to be counted was investigated in order to reduce analysis time. The traditional method of counting 420 arbitrarily chosen fields or $1 \mathrm{~mm}^{2}$ filter area was compared to 30 fields chosen in a computer generated purely random fashion, along an assumed symmetrical distribution on the radius of a filter.

\section{Method}

Houses in Soweto were chosen by convenience sampling, excluding those within $500 \mathrm{~m}$ of a major traffic highway, a formal sector service garage or within two kilometers of a disused power station. The air was sampled at flow rates of up to 4 liters per minute. The filter clearing and counting was carried out as per the AIA RTM 1 (5) Dusts in the air samples were collected on $25 \mathrm{~mm}, 1.2 \mu \mathrm{m}$, gridded cellulose ester membrane filters in open face cowled cassettes made of conductive plastic. One hundred fibers were counted at 400 times magnification with a phase contrast microscope against the background of a Walton Beckett graticule. 
Dust samples for the AIA RTM 2 sampling method were collected on goldcoated $25 \mathrm{~mm}, 1.2 \mu \mathrm{m}$, polycarbonate filters in open face cowled cassettes made of a conductive plastic. The analysis was carried out on a JEOL JSM 5600 scanning electron microscope with a Vantage EDX analyzer, counting either 420 or 30 fields at 2000 times magnification (6). Only respirable fibers were counted according to the AIA counting rules. We counted only fibers of length greater than $5 \mu \mathrm{m}$, a diameter less than $3 \mu \mathrm{m}$, with a length to diameter ratio of greater that $3: 1$ and which were not touching a particle of greater than $3 \mu \mathrm{m}$ diameter.

Two interior and one exterior sampling points at a height of approximately 1 meter (approximate breathing height of a person sitting) were chosen for each house and sampled at 3 liters/min for 3 hours or more. A fourth, personal sample collected at 1 liters $/ \mathrm{min}$ with the sampling head in the personal breathing zone was taken while cleaning the house for 5 minutes or longer.

\section{Results}

The fewer number of fields counted by RTM 2 reduced the representitiveness of the sample dramatically so that there was no correlation between the two methods of field selection, table 1. There was, however, good correlation between the two methods for non-asbestos fibers, which were more numerous. A fewer number of fields counted may be an option when sampling for asbestos in the occupational environment where asbestos fibers are more numerous.

Results of the 23 houses of which 14 houses had cement roofs showed that most houses had no detectable respirable asbestos fibers in air by the RTM 2 method. The average fiber concentration was 0.1 fiber per liter with the maximum concentration measured of 1 fiber per liter in only one of the houses after active dust generation by sweeping and sampling for 3 hours afterwards, table 2. This result must be considered to be qualitative as the limit of quantification for AIA RTM 2 is 10 fibers per liter.

Table 3 demonstrates the high specificity of the RTM2 Scanning Electron Microscope (SEM) with energy dispersive X-ray analysis when compared to the Phase contrast light microscope (PCLM) when measuring low concentrations of asbestos fibers in air. The correlation coefficient between the RTM2 SEM and the PCLM was -0.421 showing that many fibers counted by the PCM are not asbestos fibers, table 3.

Table 1: Linear correlation coefficients for different fiber types, describing the relationship between the trial methods of counting 30 randomly selected fields and the RTM 2 method, which requires counting 420 fields or an area of $1 \mathrm{~mm}^{2}$.

\begin{tabular}{|l|l|l|l|l|}
\hline Method & \multicolumn{2}{|l|}{ Count 420 fields } & \multicolumn{2}{l|}{ Count 30 random fields } \\
\hline Fiber type & Asbestos & Non Asbestos & Asbestos & Non Asbestos \\
\hline $\begin{array}{l}\text { Correlation } \\
\text { coefficient for } \mathrm{n}=14\end{array}$ & - & - & -0.08 & 0.98 \\
\hline
\end{tabular}




\section{Environmental Health Risk}

Table 2: The qualitative average concentration of asbestos fibers in asbestos and non-asbestos roofed houses. The results were less than the limit of quantification of the AIA RTM 2 method.

\begin{tabular}{|l|l|l|l|}
\hline Type of house & $\begin{array}{l}\text { Asbestos roofed } \\
\text { houses }\end{array}$ & $\begin{array}{l}\text { Non-Asbestos } \\
\text { roofed houses }\end{array}$ \\
\hline Average fiber concentration* f/liter & 0.1 & 0 \\
\hline \multicolumn{2}{|l|}{ Std. error of the mean } & 0.3 & - \\
\hline Number of houses & 14 & 9 \\
\hline $\begin{array}{l}95 \% \text { confidence } \\
\text { limits of the mean }\end{array}$ & upper & 0.2 & - \\
\cline { 2 - 4 } & lower & 0 & - \\
\hline
\end{tabular}

* Note the maximum concentration measured was 1 fiber per liter during a 3hour static sample taken in a kitchen with no ceiling, during and after a cleaner had swept the house interior.

Table 3: Results of asbestos sampling by RTM2 Scanning Electron Microscope (SEM) with energy dispersive X-ray analysis and the phase contrast light microscopy (PCLM) method and the correlation between the two methods.

\begin{tabular}{|c|c|c|c|c|c|c|}
\hline & \multicolumn{6}{|c|}{ Average fiber concentration $\mathrm{f} / \mathrm{l}$} \\
\hline \multirow{2}{*}{ Type of House } & \multirow{2}{*}{$\begin{array}{l}\text { Asbestos } \\
\text { roofed } \\
\text { houses }\end{array}$} & \multicolumn{2}{|c|}{$\begin{array}{l}95 \% \text { confidence } \\
\text { limits }\end{array}$} & \multirow{2}{*}{$\begin{array}{l}\text { Non- } \\
\text { Asbestos } \\
\text { roofed } \\
\text { houses }\end{array}$} & \multicolumn{2}{|c|}{$\begin{array}{l}95 \% \text { confidence } \\
\text { limits }\end{array}$} \\
\hline & & upper & lower & & upper & lower \\
\hline $\begin{array}{l}\text { RTM2 Scanning } \\
\text { Electron Microscope; } \\
\text { (Std. error of the } \\
\text { mean) }\end{array}$ & $0.1(0.3)$ & 0.2 & 0 & 0 & - & - \\
\hline $\begin{array}{l}\text { Phase contrast light } \\
\text { (PCLM) microscope; } \\
\text { (Std. error of the } \\
\text { mean) }\end{array}$ & $2(7)$ & 6 & 0 & $5(10)$ & 11 & 0 \\
\hline Number of Houses & \multicolumn{3}{|l|}{14} & \multicolumn{3}{|l|}{9} \\
\hline $\begin{array}{l}\text { Correlation between } \\
\text { RTM2 and PCLM }\end{array}$ & \multicolumn{3}{|l|}{-0.421} & \multicolumn{3}{|l|}{-} \\
\hline
\end{tabular}




\subsection{Morphology and recognition}

Several fibers were found attached to a particle one example is shown in figure 1. The fiber is attached to a particle greater than 3 microns and is therefore not respirable and is not counted according to the AIA counting rules.

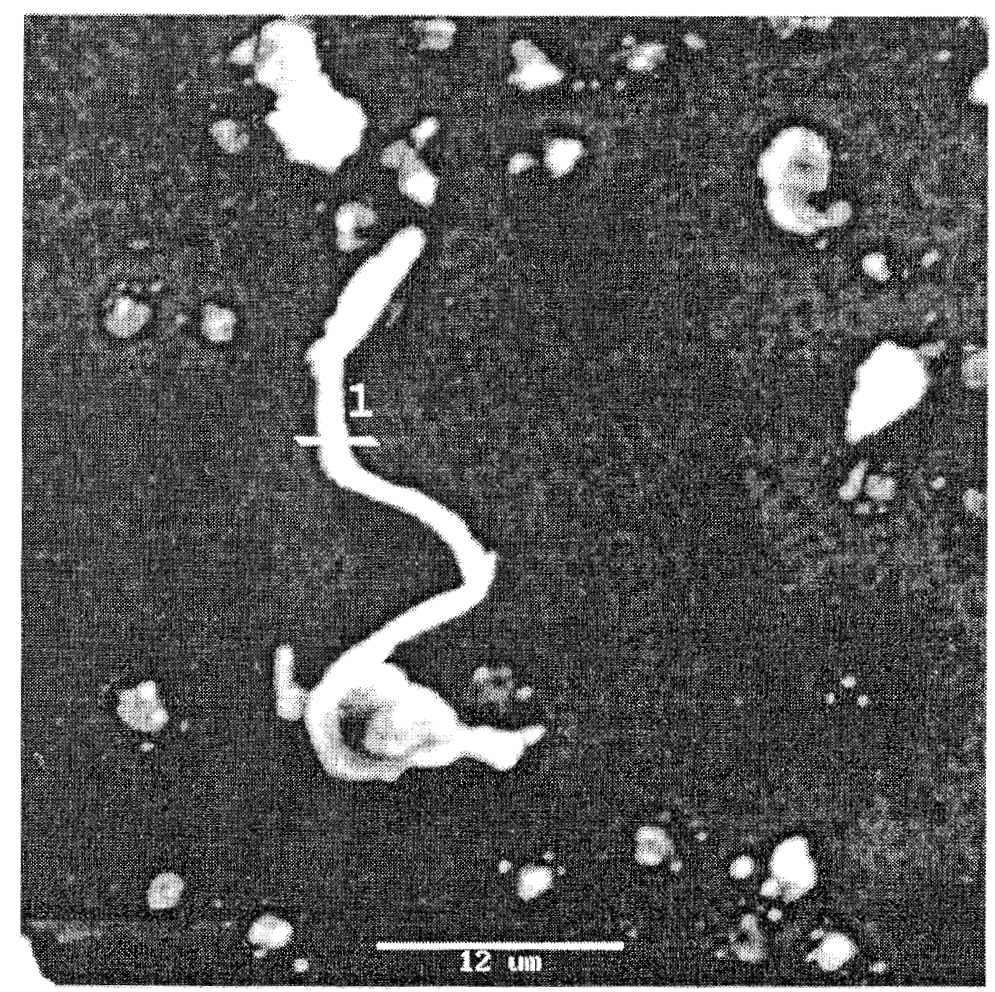

Figure 1: A non-respirable serpentine chrysotile asbestos fiber attached to a particle probably originating from the asbestos cement roof. The scan was taken at magnification $2000 \mathrm{x}$ using a scanning electron microscope on a gold coated filter. 


\section{Environmental Health Risk}

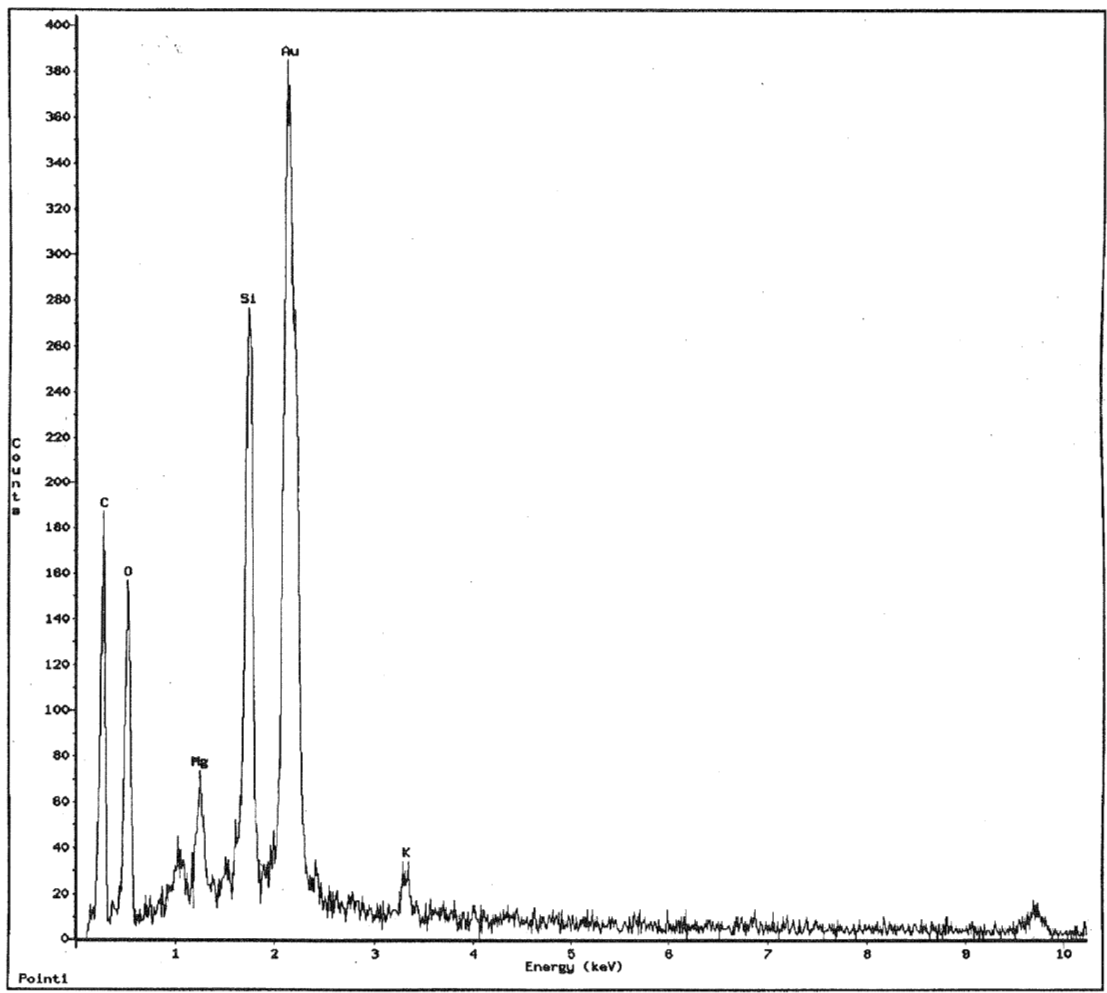

Figure 2: The Energy Dispersive X-ray (EDX) trace originating from point 1 in figure 1 . The resulting trace from the fiber showed a ratio of $\mathrm{Mg}$ to $\mathrm{Si}$ of 0.26 rather than 0.9 normally found in chrysotile fibers $\left(\mathrm{Mg}_{3} \mathrm{Si}_{2} \mathrm{O}_{5}(\mathrm{OH})_{4}\right)$. This is consistent with the more soluble magnesium element being leached out of the asbestos fibers contained in the roof by environmental stressors such as acid rain. Identification as chrysotile was based on the chemical EDX analysis of magnesium and silicon as well as the fibrous serpentine nature of the fiber seen in figure 1 .

\section{Discussion}

Asbestos was used in houses in the USA to improve thermal insulation. In a 1991 study by the National Institute for Occupational Safety and Health (NIOSH) of residents who used a low budget insulation company to insulate their houses, a maximum asbestos concentration of 20 fibers per liter was measured (7). The NIOSH study, like our Soweto study involved active fiber disturbance to simulate worst-case scenarios. A UK study in 1986 similar to the USA study but without active disturbance, used a combination of TEM and PCM to quantify asbestos exposure. In the UK a survey of 43 buildings with friablesprayed asbestos, asbestos fireproofing, asbestos in warm air heaters or other 
miscellaneous use, found that at only one site, did the concentration exceed 1 fiber per liter (8).

Our result of 0.1 fibers per liter of air sampled has a standard error of the mean of 0.3 . This result is below the limit of quantification or 'detection' reported to be 10 fibers per liter for RTM 2 and is therefore a qualitative finding. However, its significance is supported by the finding that no asbestos fibers were detected in the control houses without asbestos roofs.

The 'qualitative' average concentration of asbestos in the Soweto houses as estimated by RTM 2 by SEM of 0.1 fibers per liter of air sampled is similar to asbestos fiber concentrations found in other asbestos containing public buildings of 2 to 0.2 fibers per liter (9).

Chesson has developed a formula or mathematical approach to allow conversion from PCM measurements to transmission EM results (10). Our experience suggests that this approach may be misleading due to misclassification of fibers by PCM especially for low environmental concentrations of asbestos in air. Misclassification of fibers by PCM has also been reported in the USA and UK studies $(7,8)$.

\section{Conclusion}

Our results suggest that the AIA RTM2 method with a SEM is suitable for measuring low concentrations environmental asbestos in air while the PCM method is not. This brings into question earlier exposure measurements made in Soweto, which appear to be higher than is usually found in asbestos containing buildings.

The large number of fields counted is necessary to attain the needed accuracy. Further work could be done to determine the optimum number of fields to be counted at different expected environmental asbestos fiber concentrations.

The results of the average concentration of asbestos found in asbestos roofed houses are about one thousand times lower than the occupational environmental limit and therefore "should" carry minimal risk for asbestosis. These results are only a quarter of the complete study and are therefore preliminary.

\section{References}

[1] Botha J.S., Irwig L.M \& Strebel P. Excess mortality from stomach cancer, lung cancer and asbestosis and/or mesothelioma in crocidolite mining districts in South Africa. American Journal Epidemiology 123, pp. 30-40, 1986.

[2] Surveillance of Occupational Respiratory Diseases in South Africa: Alert - August 1999, 'Asbestos: An introduction' Published by the National Center for Occupational Health, P.O. Box 4788, Johannesburg 2000.

[3] Mathee A., Von Schirnding Y.E.R., De Wet T.\& Mokoetle K., Potential risk factors for asbestos exposure amongst six-month-old infants living in 
120 Environmental Health Risk

the township of Soweto, South Africa. International Journal Environmental Health Research 10, pp. 135-139, 2000.

[4] Mogomotsi T.E.R., Rama D.B.K.\& Du Toit R.J. Assessment of asbestos exposure levels in Soweto. "Internal National Center for Occupational Health (NCOH) Progress Report (September 1992 Revision)."

[5] Asbestos International Association Health and Safety Publication Recommended Technical Method No.1 Reference Method for the determination of airborne asbestos fibre concentrations at workplaces by light microscopy (membrane filter method) Published by Asbestos International Association, 68 Glouster Place, London W1H 3HL, England. January 1982 .

[6] Asbestos International Association Health and Safety Publication Recommended Technical Method No.2 Method for determination of airborne asbestos fibers and other inorganic fibers by SEM. Published by Asbestos International Association, 68 Glouster Place, London W1H 3HL, England, 1987 Revision.

[7] McCammon C. \& Lee S. Case Studies: Asbestos exposure during lowincome housing weatherization. Applied Occupational and Environmental. Hygiene, 6(5), pp. 347-348, 1991.

[8] Burdett G.J. \& Jaffrey S.A.M.T. Airborne asbestos concentrations in buildings. Annals of Occupational Hygiene, 30(2), pp. 185-199, 1986.

[9] Health Effects Institute - Asbestos Research: Asbestos in Public and Commercial Buildings: A Literature Review and Synthesis of Current Knowledge. Health Effects Institute - AR, Cambridge, MA, 1991.

[10] Chesson J., Rench J.D., Schultz B.D. \& Milne K.L. Interpretation of Airborne Asbestos Measurements, Risk Analysis,10(3) ,437-447, 1990. 